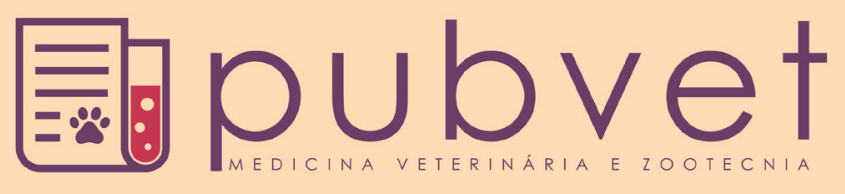

ISSN $1982-120$

HTTP://DX.DOI.ORG/10.22256/PUBVET.VI1N8.761-766

\title{
A prevalência de mastites em vacas leiteiras do município de Carlinda (MT), no ano de 2016
}

\author{
Agnaldo Cândido da Silva ${ }^{1 *}$, Frederico Fonseca da Silva ${ }^{2}$, Vanderlei Bett ${ }^{3}$ \\ ${ }^{I}$ Biólogo, - Universidade do Estado de Mato Grosso; Pós-graduado em Agroecologia pelo IFPR - Instituto Federal do Paraná. Carlinda, MT. \\ Email: agnaldocarlinda@yahoo.com.br; \\ ${ }^{2}$ Engenheiro Agrônomo, Doutor em Irrigação e Meio Ambiente, Professor e Pesquisador do IFPR - Instituto Federal do Paraná. Curitiba, \\ PR.Email: frederico.silva@ifpr.edu.br \\ ${ }^{3}$ Zootecnista e Médico Veterinário, Doutor em Zootecnia (Produção Animal), Pesquisador da Área de Nutrição Animal do IAPAR - Instituto \\ Agronômico do Paraná. Paranavai, PR. Email:vvand.bett@iapar.br \\ *Autor para correspondência
}

RESUMO. Considerando que os pequenos produtores do município de Carlinda (MT) têm como principal atividade econômica a produção de leite e, considerando que a mastite bovina se mostra como uma das causas de queda na produção do leite e desvalorização do rebanho, o objetivo deste trabalho foi o de identificar a incidência, a prevalência e as causas da ocorrência da mastite bovina na cidade de Carlinda, região norte mato-grossense. O trabalho foi realizado em 8 propriedades sendo 4 com ordenha mecânica e 4 com ordenha manual. Usou-se o CMT (Califórnia Mastitis Test). A amostra coletada foi misturada com o reagente e homogeneizada e leitura após 10 segundos. O resultado foi classificado como negativo (0), positivo que variam de traços (leve formação de gel) a fracamente positivo $(+)$, reação positiva $(++)$ e reação fortemente positiva $(+++)$. Observou-se que $87,5 \%$ do rebanho de gado leiteiro do setor dessa comunidade apresentam resultado positivo para a prevalência de mastite, sendo em $100 \%$ das propriedades de ordenha manual e $75 \%$ das com ordenha mecânica. Das vacas ordenhadas manualmente, $37,5 \%$ eram positivas no teste CMT e $62,5 \%$ negativas. Das ordenhadas mecanicamente, $30 \%$ foram positivas e $70 \%$ negativas. Das propriedades estudadas, em $62,5 \%$ delas foi considerada de higiene boa e $37,5 \%$ ruim. É importante relatar que uso de pré e pós "dipping" não foi observado em nenhuma propriedade (alguns nem conhecem os procedimentos). Diante dos resultados pode se afirmar que a mastite está presente na maioria dos rebanhos leiteiros do município de Carlinda (MT) e os tipos de ordenha não apresentaram interferência na prevalência da mastite subclínica no rebanho.

Palavras chave: Higiene, leite, mamite, ordenha, sanidade

\section{The mastitis prevalence in dairy cows in the municipality of Carlinda (Brazil), in the year of 2016}

ABSTRACT. Whereas that small producers in the municipality of Carlinda (Brazil) whose main economic activity milk production and also whereas bovine mastitis is shown as one of causes of drop in milk production and impairment of the herd, the aim of this study was to identify the incidence, prevalence and causes of the occurrence of bovine mastitis in the city of Carlinda, northern Mato Grosso State (Brazil). The study was conducted in 8 properties 4 with mechanical milking and 4 with manual milking. It used the CMT (California Mastitis Test). The collected sample was mixed and homogenized with the reagent and read after 10 seconds. The result was rated as negative (0), positive ranging from traces (light gel formation) to weakly positive $(+)$, positive reaction $(++)$ and strong positive reaction $(+++)$.It was observed that $87.5 \%$ of the dairy herd that community 
industry have tested positive for the prevalence of mastitis, being $100 \%$ the properties of milking is $75.0 \%$ with mechanical milking. From the cows milked by hand, $37.5 \%$ were positive in the CMT test and $62.5 \%$ negative, and from the cows milked mechanically, $30.0 \%$ were positive and $70.0 \%$ negative, by the same test. About the sanity in the properties studied, $62.5 \%$ of them were considered good hygiene and $37.5 \%$ bad. It is important to report that use of pre and post "dipping" was not observed in any property (some do not know the procedures). According to these results can be said that mastitis is present in most dairy herds of the municipality of Carlinda (Brazil) and types of milking did not show interference in the prevalence of subclinical mastitis in the herd.

Keywords: Hygiene, milk, mastitis, milking, sanity

\section{La prevalencia de mastitis en vacas lecheras del municipio de Carlinda (Brasil), en el año 2016}

RESUMEN. Considerando que los pequeños ganaderos del municipio de Carlinda (Brasil) tienen como principal actividad económica la producción de leche y, considerando que la mastitis bovina se presenta como una de las causas de disminución en la producción de leche y devaluación del rebaño, el objetivo de este trabajo fue identificar la incidencia, la prevalencia y los orígenes de la casuística de la mastitis bovina en Carlinda, región norte mato-grossense. El trabajo fue realizado en ocho propiedades siendo cuatro con ordeño mecánico y cuatro con ordeño manual. Se utilizó el CMT (Prueba de Mastitis California). La muestra colectada fue mezclada con el reactivo, homogeneizado y leída después de 10 segundos. El resultado fue clasificado como negativo (0), positivo que varía de trazas (ligera formación de gel) a positivo débil $(+)$, positivo evidente $(++)$ y positivo fuerte $(+++)$. Se observó que el $87,5 \%$ del rebaño de ganado lechero del sector de esa comunidad presentaba resultado positivo para la prevalencia de mastitis, siendo en el $100 \%$ de las propiedades de ordeño manual y el $75 \%$ en las propiedades con ordeño mecánico. De las vacas ordeñadas manualmente, el $37,5 \%$ eran positivas en el test CMT y el $62,5 \%$ negativas. De las ordenadas mecánicamente, el $30 \%$ fueron positivas y el $70 \%$ negativas. De las propiedades estudiadas, en el $62,5 \%$ de ellas se consideró de buena higiene y un $37,5 \%$ malo. Es importante relatar que el uso de pre y post "dipping" no fue observado en ninguna propiedad (algunos ni siquiera conocen los procedimientos). Ante los resultados se puede afirmar que la mastitis está presente en la mayoría de los rebaños lecheros del municipio de Carlinda (Brasil) y los tipos de ordeño no presentaron interferencia en la prevalencia de la mastitis subclínica en el rebaño.

Palabras clave: Higiene, leche, mamitis, ordeño, sanidad

\section{Introdução}

O Estado de Mato Grosso é considerado hoje um dos grandes produtores de leite do Brasil e aparece em $9^{\circ}$ lugar no ranking brasileiro, com uma produção próxima dos 700 milhões de litros ao ano, conforme dados do Instituto Brasileiro de Geografia e Estatística (ANUALPEC, 2016).

Considerando que a bovinocultura leiteira tem importante papel no contexto sócio-econômico de qualquer região, a pecuária leiteira é dentre os setores econômicos da produção animal, a atividade que mais fixa e mantêm o homem no campo contribuindo para sobrevivência e desenvolvimento social. Caracterizada como atividade de exploração animal, a produção de leite e a verticalização do setor de laticínios é um empreendimento que gera renda, agrega tecnologia e desenvolve o meio rural (Barros, 2008, Teixeira Júnior et al., 2015). $\mathrm{Na}$ mesorregião Norte Mato-Grossense, a bovinocultura leiteira é importante atividade econômica para as pequenas propriedades. Esta mesorregião possui $41,8 \%$ do rebanho do Estado, com produtividade média diária chegando a 3,4 L/dia, média igual à do Estado; porém, inferior que à nacional, que é de 4,1 L/dia (ANUALPEC, 2016).

A criação de bovinos leiteiros na Região Amazônica revela-se como atividade pecuária importante em função do menor custo da terra e de sua favorável condição edafo-climática. Pois, de acordo com Faminow (1998); IBGE (2000); 
Ferreira (2006), citados por Barros (2008) concordam que, considerando-se apenas o aspecto socioeconômico, nessa região o gado leiteiro representam não apenas um meio de subsistência do homem ou fator de diminuição do êxodo rural (Assis et al., 2005), mas uma atividade que têm contribuído para melhoria da renda familiar (Deresz, 2001) e, quando explorada de forma otimizada, pode fornecer retorno econômico ao produtor, sendo um forte fator de consolidação dos estabelecimentos rurais, considerando a existência do mercado consumidor (Assis et al., 2005). Esta atividade tem se caracterizado como um fator importante nas perspectivas de crescimento para geração de emprego e renda e, consequentemente, melhoria no padrão de vida da comunidade, evita o êxodo rural das famílias que vivem em função dessa atividade econômica.

Considerando a importância desta atividade para os pequenos produtores voltados a pecuária leiteira bem como a influencia econômica para a região, a situação atual da bovinocultura leiteira nesta região, em especial no município de Carlinda (MT), parece indicar a necessidade de realização de estudos, quando se observa o panorama local da produção leiteira e seus entraves e os fatores de ordem sanitária que afetam a produção.

A sanidade do rebanho é um dos fatores mais importantes para o bom desempenho na atividade. A saúde do animal interfere na evolução da produtividade do rebanho e, por consequência, da produção na propriedade. Também pode trazer prejuízos socioeconômicos pela transmissão de zoonoses aos contactantes e consumidores (Poletto et al., 2004). Neste sentido, uma das doenças de cunho econômico mais relevante em toda cadeia produtiva do leite é a mastite, prejuízos que vão desde a redução da produção de leite, descarte ou redução do valor comercial dos animais infectados, perdas na evolução genética do rebanho, gastos com medicamentos e mão de obra extra, até aos laticínios que tem a qualidade dos produtos derivados prejudicado pela alteração da qualidade físico-química do leite (Costa et al., $\underline{2013}$ ).

De acordo com os produtores entrevistados, a mastite bovina tem sido fator importante na perda econômica e diminuição da renda familiar, caracterizado principalmente pela diminuição da produção diária, aumento na mão de obra, e descarte do animal (Costa et al., 1995, Veiga, 1998). Confirmando o que diz Benites (1999), que relaciona a mastite como um dos mais graves problemas sanitários da pecuária leiteira e que determina elevados prejuízos econômicos decorrentes de queda na produção e diminuição da qualidade do leite, afetando rebanhos leiteiros em todas as regiões geoeconômicas do País.

Além disso, autores como Veiga (1998) e Sena (2000) afirmam que a mastite é uma doença que acarreta elevados prejuízos à produção de leite, com perdas financeiras, decorrentes de tratamentos, mão de obra especializada, descarte de animais, depreciação no valor e redução na produção de leite. Sendo esta última o fator individual mais importante das perdas econômicas em decorrência da mastite bovina. Mastite é uma inflamação da glândula mamária, geralmente causada pela infecção por diversos tipos de microrganismos, sendo as bactérias os principais agentes. É a doença mais importante dos rebanhos leiteiros em todo o mundo devido à alta incidência de casos clínicos, alta incidência de infecções não perceptíveis a olho nu (infecções subclínicas) e aos prejuízos econômicos que acarreta (Tozzetti et al., 2008).

É importante frisar que a mastite bovina pode ser causada por uma grande variedade de agentes, incluindo bactérias, microplasmas, leveduras, fungos e algas. Embora mais de 137 espécies, subespécies e sorotipos de microrganismos já tenham sido isolados de infecções da glândula mamária bovina, a maioria das infecções é causada por bactérias (Tozzetti et al., 2008). Podendo ainda ter origem as causas tóxica, traumática, alérgica, metabólica ou infecciosa. De acordo com Costa et al. (1995), no caso das infecciosas tem se destacado as bactérias do gênero Staphylococcus como um dos agentes mais presentes nos casos de mastite.

Os pequenos produtores do município de Carlinda (MT) têm como principal atividade econômica a produção de leite e, considerando que a mastite bovina tem se apresentado como uma das causas de queda na produção do leite e desvalorização do rebanho.

Este trabalho foi realizado para identificar a incidência, a prevalência e as causas da ocorrência da mastite bovina na cidade de Carlinda, região norte mato-grossense.

\section{Material e Métodos}

O trabalho foi realizado em oito propriedades sendo 4 com ordenha mecânica e 4 com ordenha manual, de uma comunidade da região, cujo 
primeiro autor tem acompanhado tecnicamente, a mais de 25 anos.

Para realizar o teste usou-se uma placa própria para esta finalidade (uma raquete contendo quatro cavidades) e o CMT (Califórnia Mastite Test) que é um teste muito empregado para identificar vacas com mastite subclínica em propriedades rurais onde o exame de laboratório é inviável. Como rotina, após a coleta do leite, consistiu em misturar o material coletado com o reagente, depois homogeneizá-lo e fazer a leitura após 10 segundos. De acordo com a quantidade de células somáticas do leite, forma-se um gel, de espessura variada. Se a quantidade de células somáticas é baixa, não forma gel, o resultado é negativo. De acordo com a espessura do gel formado, ou seja, da reação, o resultado é classificado como negativo (0), positivo que variam de traços (leve formação de gel) a fracamente positivo $(+)$, reação positiva $(++)$ e reação fortemente positiva $(+++)$, conforme citado por Fonseca (2000).

\section{Resultados e Discussão}

Inicialmente, para o público ao qual se destina o trabalho, ressalta-se que este se ateve mais em constatar a positividade ou não para mastite nos rebanhos pesquisados.

Ao todo, foram feitos testes em 80 vacas. Sendo que dessas, 30 apresentaram resultados positivos para o teste de Mastite subclínica; e, dos oito rebanhos pesquisados, sete foram positivos para mastite subclínicas para o CMT (Tabela 1).

Tabela 1. Prevalência da mastite quanto às propriedades e tipo de ordenha

\begin{tabular}{lccc}
\hline $\begin{array}{l}\text { Tipo de ordenha } \\
\text { propriedade }\end{array}$ & Positivo & Negativo & $\%$ \\
\hline Mecânica & 03 & 01 & 75 \\
Manual & 04 & 00 & 100 \\
Total & 07 & 01 & 87,5 \\
\hline
\end{tabular}

Ou seja, desta forma, conclui-se que $87,5 \%$ do rebanho de gado leiteiro do setor dessa comunidade apresentam resultado positivo para a prevalência de mastite. Sendo que, quando comparado ao tipo de ordenha, nos currais onde a ordenha é manual, a mastite está presente em $100 \%$ das propriedades. Já nas de ordenha mecânica, o índice é de 75\%, conforme apresenta o Gráfico 1.

Foram testadas 80 vacas para o teste de CMT, 40 vacas eram ordenhadas manualmente e 40 vacas eram ordenhas mecanicamente. Das vacas ordenhadas manualmente, $37,5 \%$ (15 vacas) eram positivas no teste CMT e 62,5\% (25 vacas) tiveram eram negativas. Nas vacas ordenhadas mecanicamente, $30 \%$ (12 vacas) foram positivas e $70 \%$ (28 vacas) foram negativas. Estes dados evidenciam que a ordenha mecânica favorece a higiene e, consequentemente, a manutenção mais eficiente da saúde do úbere. Por outro lado, a ordenha manual favorece a proliferação dos microrganismos causadores da mastite.

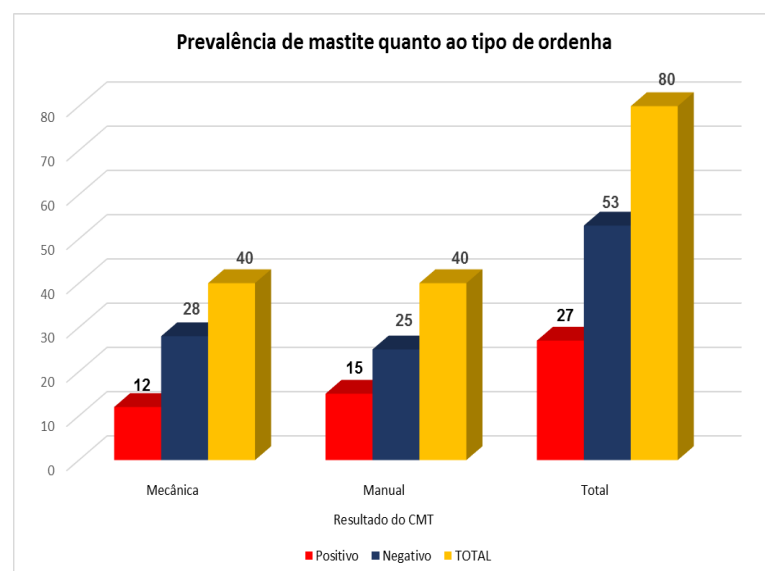

Gráfico 1. Prevalência da mastite quanto às propriedades e tipo de ordenha

No cômputo geral, das 80 vacas avaliadas dos rebanhos estudados, $33,8 \%$ (27 vacas) são positivas para mastite subclínica.

A higiene do ambiente tem especial contribuição sobre a prevalência da mastite nos rebanhos. Das propriedades estudadas, em $62,5 \%$ delas foi considerada de higiene boa e $37,5 \%$ ruim.

Pode se ainda observar que a presença de mastite no rebanho está diretamente relacionada ao manejo e cuidados dispensados aos animais em lactação, por isso sugere-se a adoção de medidas de prevenção que devem englobar, além de adequações técnicas (ordenha higiênica, procedimentos e equipamentos corretos, instalações adequadas) e o treinamento de ordenhadores, para controlar e mesmo diminuir o número de animais acometidos pela doença.

Quando se avaliou os ordenadores, 87,5\% foram considerados de boa higiene e $12,5 \%$ ruins.

É importante relatar que uso de pré e pós "dipping" não foi observado em nenhuma propriedade (alguns nem conhecem os procedimentos). E ainda a falta de hábitos de higiene do ordenhador e utensílios empregados na ordenha, condição que pode justificar os índices relevantes para mastite subclínicas. 
Outro fator importante verificado foram as perdas econômicas que ocorrem nas propriedades em função da mastite devidas à redução na produção, ao descarte de leite e de animais, aos gastos com medicamentos, com serviços veterinários e com o aumento da mão de obra e, em alguns casos, à morte ou descarte do animal. A Tabela 2 apresenta essas estimativas de perdas.

Tabela 2. Estimativa de perdas, em média, por propriedades, que já descartou animais em função da perda de mamários por mastite, descarte do leite e outros gastos (tratamento).

\begin{tabular}{|c|c|c|c|c|c|c|}
\hline \multicolumn{2}{|c|}{ Propriedades } & \multicolumn{2}{|c|}{ Animais descartados $(\mathrm{R} \$)$} & \multirow{2}{*}{$\begin{array}{c}\begin{array}{c}\text { Descarte do leite (por } \\
\text { mês) }\end{array} \\
270,00\end{array}$} & \multirow{2}{*}{$\begin{array}{r}\text { Outros gastos } \\
160,00\end{array}$} & \multirow{2}{*}{$\begin{array}{r}\text { Total } \\
1.330,00\end{array}$} \\
\hline A & \multirow{4}{*}{ 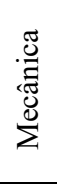 } & 2 & 900,00 & & & \\
\hline B & & 0 & 0,00 & 0,00 & 0,00 & 0,00 \\
\hline $\mathrm{C}$ & & 3 & $1.350,00$ & 450,00 & 250,00 & $2.050,00$ \\
\hline$\underline{\mathrm{D}}$ & & 3 & $1.350,00$ & 360,00 & 200,00 & $1.910,00$ \\
\hline A & \multirow{4}{*}{ 吾 } & 1 & 450,00 & 360,00 & 200,00 & $1.010,00$ \\
\hline B & & 1 & 450,00 & 360,00 & 200,00 & $1.010,00$ \\
\hline $\mathrm{C}$ & & 3 & $1.350,00$ & 360,00 & 200,00 & $1.910,00$ \\
\hline$\underline{D}$ & & 2 & 900,00 & 270,00 & 160,00 & $1.330,00$ \\
\hline
\end{tabular}

Os resultados deste estudo apontam para uma concordância com o que afirmam Machado et al. (2000) quando dizem que no Brasil pode-se afirmar que a mastite subclínica está presente em todos os rebanhos leiteiros. Pois, vários levantamentos realizados a partir de 1992 indicam alta ocorrência, com índices variando de $14,4 \%$ a $58,8 \%$ de vacas infectadas por rebanho (Harmon, 2001).

As observações relativas aos fatores de risco indicaram para uma preocupação sanitária dos rebanhos de interesse público e que há realmente a necessidade de os produtores de leite melhorar as condições higiênicas de ordenha e adotem as práticas atuais de controle de mastite. $\mathrm{O}$ controle da sanidade do úbere torna-se importante para que o leite produzido tenha a qualidade exigida pela Instrução Normativa $\mathrm{n}^{\mathrm{o}}$ 62, de 29 de dezembro de 2011, do Ministério da Agricultura, Pecuária e Abastecimento (Brasil, 2003).

\section{Conclusões}

Diante dos resultados pode se afirmar que a mastite está presente na maioria dos rebanhos leiteiros do município de Carlinda (MT) quando considerado a forma subclínica da doença.

Os tipos de ordenha (manual e mecânica) não apresentou interferência na prevalência da mastite subclínica no rebanho.

A higiene do curral e do ordenhador destacamse como principal disseminador das contaminações da mastite bovina.

\section{Referências Bibliográficas}

ANUALPEC. 2016. Anuário da Pecuária Brasileira, 20th edn. Instituto FNP, São Paulo, SP, Brasil.

Assis, A. G., Stock, L. A., Campos, O. F., Gomes, A. T., Zoccal, R. \& Silva, M. R. 2005. Sistemas de produção de leite no Brasil. EMBRAPA. EMBRAPA, Juiz de Fora.

Barros, B. C. V. 2008. Mastite bovina em rebanhos leiteiros no município de Parauapebas, mesorregião sudeste do estado do Pará. Universidade Federal do Pará, Belém, Pará.

Benites, N. R. 1999. Estudo morfométrico de mastite bovina em vacas naturalmente infectadas. São Paulo, Brasil.

BRASIL. 2003. Ministério da Agricultura, Pecuária e Abastecimento. Instrução Normativa $\mathbf{n}^{\mathbf{0}}$ 62, de 18 de setembro de 2004. Oficializa os Métodos Analíticos Oficiais para Análises Microbiológicas para Controle de Produtos de Origem Animal e Água, 2003. Diário Oficial da União, Brasília, 18 set. Seção 1, p. 14.

Costa, E. O., Carciofi, A. C., Benites, N. R., Melville, P. A., Pardo, R. B., Ribeiro, A. R. \& Watanabe, E. T. 1995. Estudo etiológico da mastite clínica bovina. Revista Brasileira de Medicina Veterinária, 17, 156-158.

Costa, G. M., Barros, R. A., Costa Custódio, D. A., Pádua Pereira, U., Figueiredo, D. J. \& Silva, N. 2013. Resistência a antimicrobianos em Staphylococcus aureus isolados de mastite 
em bovinos leiteiros de Minas Gerais, Brasil. Arquivos do Instituto Biológico, 80, 297-302.

Deresz, F. 2001. Produção de leite de vacas mestiças Holandês x Zebu em pastagem de capim-elefante, manejada em sistema rotativo com e sem suplementação durante a época das chuvas. Revista Brasileira de Zootecnia, 30, 197-204.

Fonseca, L. F. L. 2000. Qualidade do leite e controle de mastite, 1st edn. Lemos Editorial, São Paulo, SP, BR.

Harmon, B. 2001. Somatic cell counts: a primer. Annual Meeting-National Mastitis Council Incorporated. National Mastitis Council, USA.

Machado, P. F., Pereira, A. R., Silva, L. F. P. \& Sarriés, G. 2000. Células somáticas no leite em rebanhos brasileiros. Scientia Agrícola, 57, $359-61$.

Poletto, R., Kreutz, L. C., Gonzales, J. C. \& Barcellos, L. J. G. 2004. Prevalência de tuberculose, brucelose e infecções víricas em bovinos leiteiros do município de Passo Fundo, RS. Ciência Rural, 34, 595-598.

Sena, M. J. 2000. Perfil epidemiológico, resistência a antibióticos e aos conservantes nisina e sistema lactoperoxidase de Staphylococcus $s p$. isolados de queijos coalho comercializados em Recife-PE. Universidade Federal de Minas Gerais, Belo Horizonte.

Teixeira Júnior, F. E. P., Lopes, M. A. \& Ruas, J. R. M. 2015. Efeito do pagamento por qualidade do leite na rentabilidade da atividade leiteira. Revista do Instituto de Laticínios Cândido Tostes, 70, 24-34.

Tozzetti, D. S., Bataier, M. B. N., Almeida, L. R. \& Piccinin, A. 2008. Prevenção, controle e tratamento das mastites bovinas-revisão de literatura. Revista Científica Eletrônica de Medicina Veterinária, 6, 1-7.

Veiga, V. M. O. 1998. Diagnóstico da mastite bovina. Embrapa, Juiz de Fora, Minas Gerais.

\section{Article History:}

Received 22 March 2017

Accepted 30 May 2017

Available on line 20 June 2017

License information: This is an open-access article distributed under the terms of the Creative Commons Attribution License 4.0, which permits unrestricted use, distribution, and reproduction in any medium, provided the original work is properly cited. 